\title{
Efficacy of Drug Eluting Stent Versus Cobalt-Chromium Bare-Metal Stent in Small Artery Stenosis in Non Diabetic Patients with acute coronary syndrome
}

K.E.Alrabbat ${ }^{1}$, A.A.Reda ${ }^{2}$, T.S.Khalii ${ }^{2}$, A.M.El Kersh ${ }^{2}$, and H.A.Abd El Rahman ${ }^{1}$

${ }^{1}$ Cardiology Dept., Faculty of Medicine, Benha Univ., Benha, Egypt

${ }^{2}$ Cardiology Dept., Faculty of Medicine, Menofia Univ., Menofia, Egypt

E-Mail: Hemly@gmail.com

\begin{abstract}
Coronary artery disease (CAD) is the most common cause of morbidity and mortality in the world, This study aimed to compare cobalt-chromium BMS with DES in small artery stenosis in non-diabetic patients with ACS according to patients' clinical characteristics, acute and late results. the examination was led on 100 non-diabetic patients conceded with intense coronary condition and alluded to Cath. As per kind of stent utilized in mediation, the patients were arranged into: DES gathering: included 50 patients with sedate eluting stents to treat all over again coronary sores. BMS gathering: included 50 patients with cobalt chromium stents to treat anew coronary injuries. Every patient was exposed to full history taking, total clinical assessment, ECG, echocardiography, and serum creatinine. 5\% of patients had composite end point, ISR and MI following a half year of development while $4 \%$ of patients had TVR and $1 \%$ of patients had CABG. Just a single patient passed on in our examination. There was no noteworthy contrast among DES and BMS bunch with respect to coronary angiographic, procedural information and clinical results during development. the utilization of medication eluting stent versus cobalt chromium stent was related with a decrease in target vessel revascularization in little supply route stenosis through half year catch up with no distinction in death and nonfatal myocardial dead tissue.
\end{abstract}

Keywords: Drug Eluting Stent, Metal Stent, Small Artery Stenosis, Acute coronary syndrome.

\section{Introduction}

Coronary conduit ailment (CAD) is the most widely recognized reason for bleakness and mortality on the planet [1].The treatment for CAD has been changed altogether since the presentation of percutaneous coronary mediations (PCIs) including percutaneous transluminal coronary corridor angioplasty (PTCA) and coronary supply route stenting (CAS), PTCA was the main achievement of PCI performed by Andreas Gruentzig in the late 1970s [2].

Notwithstanding, its further improvement was impeded by one significant confinement restenosis, up to $30 \%-60 \%$ of patients had repeat of their malady inside the initial a half year [3].

The second achievement of PCI was advancement of the uncovered metal stent (BMS) in the late 1980s, which successfully decreased restenosis contrasted with PTCA alone [3]. Be that as it may, with the wide utilization of BMS, another issue approached: in-stent restenosis (ISR), [1]. At that point, the PCI was advanced toward to the third achievement, medicate eluting stents, in the mid 2000s [4].

A medication eluting stent (DES), is intended to forestall ISR through restraint of smooth muscle cell (SMC) multiplication. Original DES: The original of DESs, Cipher (sirolimus-eluting stent, Cordis, Warren, NJ) and Taxus (paclitaxel-eluting stent, Boston Scientific, Natick, MA), These two DES were endorsed by US FDA in 2002-2003 [5].

In any case, an expansion in the pace of myocardial localized necrosis (MI) and cardiovascular mortality was accounted for in patients at year and a half to 3 years after the implantation of Cipher and Taxus [6]. These occasions were seen as because recently stent apoplexy (LST). Besides, a few examinations have shown that DESs have higher paces of major unfriendly heart occasions (MACE) contrasted and BMS [7].
New-Generation DES:- The cobalt chromium $(\mathrm{CoCr})$ with more slender swaggers $(80-90 \mu \mathrm{m})$ was utilized in the second era of DESs, Xience V (everolimus-eluting stent, Abott Vascular, Santa Clara, CA) and Endeavor (zotarolimus-eluting stent, Medtronic Vascular, Santa Rosa, CA), bringing about diminished neointimal reaction and increasingly quick reendothelialization. These last two DES stages were affirmed by US FDA in 2008 [8].

The advantageous clinical information on DES are fundamentally gotten from preliminaries contrasting DES and original thick-swagger treated steel BMS. Nonetheless, results can be distinctive between stents relying upon material and structure. Stents with more slender swaggers have demonstrated less restenosis and less rehashed mediations. This impact might be because of increasingly quick reendothelialization after arrangement of more slender swagger stents, diminishing vascular injury and aggravation. With the dynamic advancement of BMS fabricating, the utilization of cobalt chromium combination has seemed promising. This compound has demonstrated great biocompatibility and seemed to constrain the antagonistic proliferative reaction seen with different combinations. What's more, cobalt-chromium contrasted and treated steel permits decrease in swagger thickness with expanded adaptability, monitoring both spiral quality and deliverability [9].

In any case, DES are notably more costly than BMS. On the off chance that most stents utilized were DES it would affect numerous emergency clinic spending plans and lead to troublesome conversations among doctors and medical clinic managers concerning which patients ought to or could be treated with DES. Signs for utilization of DES focused at explicit injuries or patients were recommended, yet such focusing on may be viewed as proportioning, especially by the patient. Since proof from controlled examinations is 
missing, neighborhood arrangements change broadlybased on translation of accessible information, spending plans, protection plans, accessibility of DES, and convictions. Moreover, third-age, uncovered metal cobalt-chromium stents are currently accessible, however no imminent correlations of DES with these more up to date BMS have been distributed so far [10].

This investigation focused on correlation of cobalt chromium BMS with tranquilize eluting stents in little conduit stenosis in non-diabetic patients with intense coronary condition as per patients' clinical qualities, intense and late outcomes.

\section{Patients and methods}

From December 2018 to December 2019, (100) randomly selected patients with ACS who were admitted to Zaitoun Specialized Hospital, were included in our study. ACS was defined as new-onset or worsening chest pain occurring at rest or with minimal exertion and not improved by nitroglycerin and or rest. Diagnosis of ACS on the basis of:

- Typical chest pain $\geq 20$ minute or atypical chest pain with suggestion of ACS.

- ECG finding as (ST segment deviation $\geq 1 \mathrm{~mm}$, inverted $\mathrm{T}$ wave, hyper acute $\mathrm{T}$ wave)

- Cardiac enzymes and troponin elevation.

According to type of stent used in intervention, the patients were classified into

- DES group: included 50 patients with drug eluting stents to treat de novo coronary lesions.

- BMS group: included 50 patients with cobalt chromium stents to treat de novo coronary lesions.

\section{Inclusion criteria}

Non diabetic patients with acute coronary syndrome referred to Cath. Lab for primary PCI to small artery stenosis with diameter less than $3 \mathrm{~mm}$ and length less than $25 \mathrm{~mm}$ whether BMS or DES according to the decision of the physician.

\section{Exclusion criteria}

Table (1) Comparison between the studied groups regarding the baseline characteristics.

\begin{tabular}{|c|c|c|c|}
\hline Baseline characteristics & DES & BMS & P-value (Sig.) \\
\hline Count & 50 & 50 & \\
\hline Age (years) & & & \\
\hline Mean \pm SD & $49.4 \pm 10.4$ & $49.8 \pm 8.2$ & $0.848(\mathrm{NS})$ \\
\hline Risk factors & & & \\
\hline Male gender & $36(72 \%)$ & $34(68 \%)$ & $0.663(\mathrm{NS})$ \\
\hline HTN & $23(46 \%)$ & $20(40 \%)$ & $0.545(\mathrm{NS})$ \\
\hline Smoking & $25(50 \%)$ & $30(60 \%)$ & $0.315(\mathrm{NS})$ \\
\hline Dyslipidemia & $28(56 \%)$ & $26(52 \%)$ & $0.688(\mathrm{NS})$ \\
\hline Obesity & $22(44 \%)$ & $19(38 \%)$ & $0.542(\mathrm{NS})$ \\
\hline Family history & $17(34 \%)$ & $19(38 \%)$ & 0.677 (NS) \\
\hline
\end{tabular}

$\mathrm{p}<0.05$ is significant.

Sig.: significance.
1- Multi vessels disease.

2- Diabetic patients.

3- Lesions longer than $25 \mathrm{~mm}$.

4- Lesions with diameter more than $3 \mathrm{~mm}$.

5- Post CABG.

6- Restenotic lesions.

Each patient was subjected to full history taking, complete clinical examination, ECG, echocardiography, and serum creatinine.

\subsection{Statistical analysis}

Information were broke down utilizing Statistical Program for Social Science (SPSS) form 25.0 for windows (SPSS Inc., Chicago, IL, USA). Quantitative information of typical dissemination were communicated as mean \pm standard deviation (SD). Middle and between quartile extend (IQR) were additionally determined for quantitative information with anomalous conveyance. Subjective information were communicated as recurrence and rate. The accompanying tests were done: Independent-examples ttrial of essentialness was utilized when contrasting between two methods for typically circulated information. Mann Whitney $U$ test is utilized to look at contrasts between two autonomous gatherings when the needy variable is consistent, however not typically disseminated. Chi-square (X2) test additionally called Pearson's chi-square test or the chi-square trial of affiliation, is utilized to find if there is a connection between two absolute factors.

\section{Results}

One hundred patients were included in this stidy, mean age was $49.6 \pm 9.3$ years. 70 patients $(70 \%)$ were males. 43 patients $(43 \%)$ were hypertensive, 55 patients (55\%) were smokers, 54 patients (54\%) had dyslipidemia, and 41 patients $(41 \%)$ were obese. +ve family history was in 36 patients $(36 \%)$. Table 1 shows a comparison between groups regarding their characteristics.

There was no significant difference between DES and BMS group regarding ECG and clinical data Table (2). 
Table (2) Comparison between the studied groups regarding the ECG and clinical data.

\begin{tabular}{|c|c|c|c|}
\hline ECG and clinical data & DES & BMS & P-value (Sig.) \\
\hline Count & 50 & 50 & \\
\hline \multicolumn{4}{|l|}{ ECG } \\
\hline Anterior & $17(34 \%)$ & $19(38 \%)$ & $0.894(\mathrm{NS})$ \\
\hline Inferior & $23(46 \%)$ & $22(44 \%)$ & \\
\hline Lateral & $7(14 \%)$ & $5(10 \%)$ & \\
\hline Extensive anterior & $3(6 \%)$ & $4(8 \%)$ & \\
\hline \multicolumn{4}{|l|}{ Killip class } \\
\hline Class 1 & $40(80 \%)$ & $38(76 \%)$ & 0.549 (NS) \\
\hline Class 2 & $9(18 \%)$ & $10(20 \%)$ & \\
\hline Class 3 & $1(2 \%)$ & $2(4 \%)$ & \\
\hline \multicolumn{4}{|l|}{ Heart rate (beat/min) } \\
\hline Median (IQR) & $83(70-93)$ & $80(69-91)$ & $0.340(\mathrm{NS})$ \\
\hline \multicolumn{4}{|l|}{ SBP (mmHg) } \\
\hline Median (IQR) & $120(110-130)$ & $120(110-130)$ & $0.711(\mathrm{NS})$ \\
\hline \multicolumn{4}{|l|}{ DBP (mmHg) } \\
\hline Median (IQR) & $70(70-90)$ & $70(80-90)$ & $0.493(\mathrm{NS})$ \\
\hline
\end{tabular}

$$
\mathrm{p}<0.05 \text { is significant. } \quad \text { Sig.: significance. }
$$

There was no significant difference between DES and BMS group regarding EF and s. creatinine Table (3).

Table (3) Comparison between the studied groups regarding the echocardiographic and laboratory data.

\begin{tabular}{lccc}
\hline Echocardiographic and laboratory data & DES & BMS & P-value (Sig.) \\
\cline { 1 - 3 } Count & 50 & 50 & \\
EF $(\%)$ & & & \\
$\quad \begin{array}{l}\text { Mean } \pm \text { SD } \\
\text { S. Creatinine (mg/dL) } \\
\text { Mean } \pm \text { SD }\end{array}$ & $58.4 \pm 7.6$ & $56.6 \pm 5.9$ & 0.204 (NS) \\
\cline { 1 - 3 }
\end{tabular}

$$
\mathrm{p}<0.05 \text { is significant. } \quad \text { Sig.: significance. }
$$

There was no significant difference between DES and BMS group regarding coronary angiographic and procedural data Table (4).

Table (4) Comparison between the studied groups regarding the Coronary angiographic and procedural data.

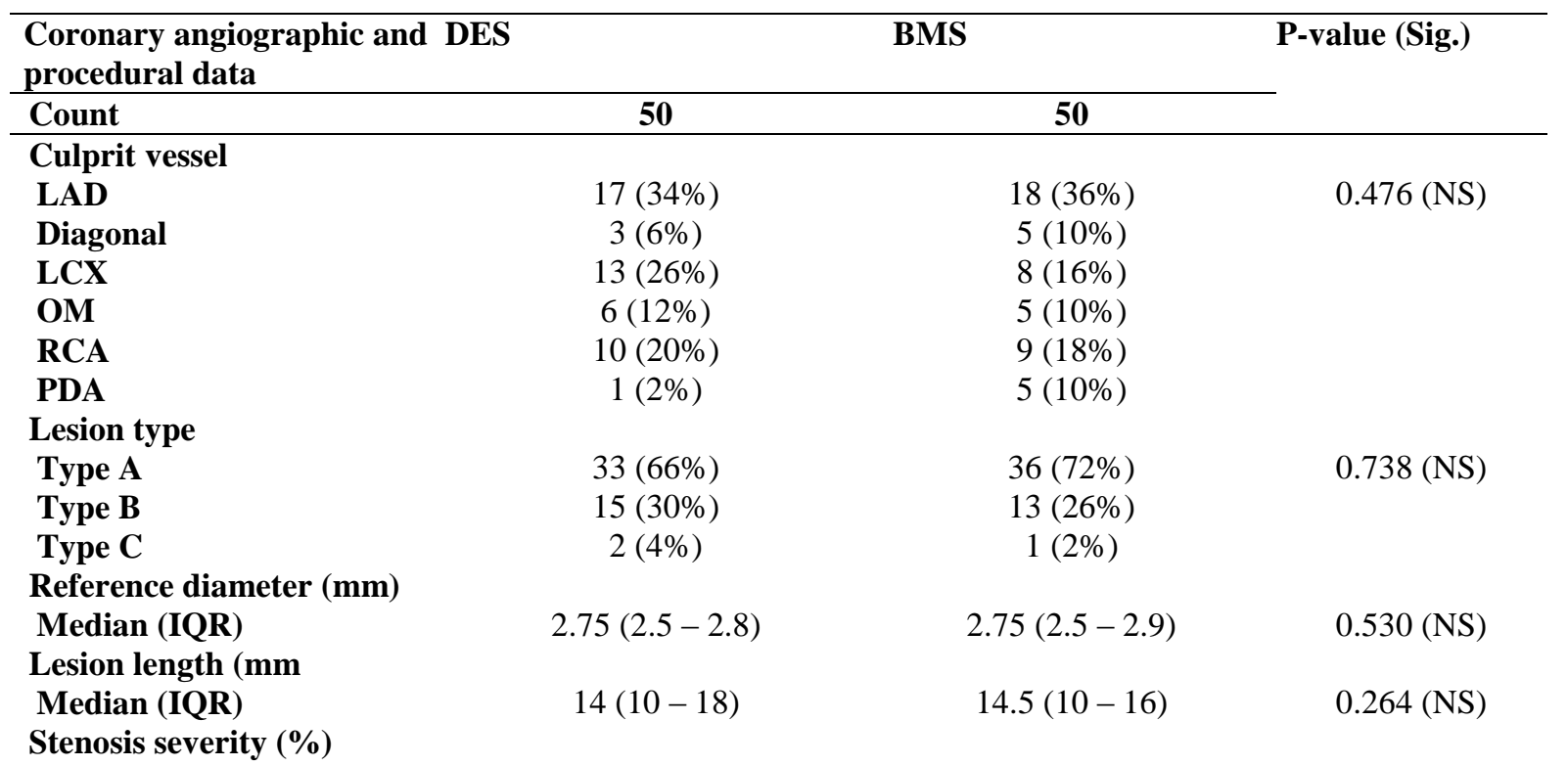


Table (4) Continue

\begin{tabular}{lccc}
\hline $\begin{array}{l}\text { Median (IQR) } \\
\text { Stent length (mm) } \\
\text { Median (IQR) }\end{array}$ & $90(80-95)$ & $90(80-96.25)$ & $0.810(\mathrm{NS})$ \\
$\begin{array}{l}\text { Stent diameter (mm) } \\
\text { Median (IQR) }\end{array}$ & $18(17.25-23.25)$ & $18(18-24)$ & 0.220 (NS) \\
\hline
\end{tabular}

$\mathrm{p}<0.05$ is significant.

Sig.: significance.

There was no significant difference between DES and BMS group regarding clinical outcomes during follow up Table (5).

Table (5) Comparison between the studied groups regarding the clinical outcomes during follow-up.

\begin{tabular}{llll}
\hline Clinical outcomes & DES & BMS & P-value (Sig.) \\
\cline { 1 - 2 } Count & 50 & 50 & \\
Composite end-point & $\mathbf{6 - m o n t h}$ outcomes & & $1.000(\mathrm{NS})$ \\
ISR & $2(4 \%)$ & $3(6 \%)$ & $1.000(\mathrm{NS})$ \\
MI & $2(4 \%)$ & $3(6 \%)$ & $1.000(\mathrm{NS})$ \\
TVR & $2(4 \%)$ & $3(6 \%)$ & $0.617(\mathrm{NS})$ \\
CABG & $1(2 \%)$ & $3(6 \%)$ & $1.000(\mathrm{NS})$ \\
Death & $0(0 \%)$ & $1(2 \%)$ & $1.000(\mathrm{NS})$ \\
\hline
\end{tabular}

$\mathrm{p}<0.05$ is significant.

Sig.: significance.

\section{Discussion}

In the current examination, there was no factually noteworthy distinction between the two gatherings concerning pattern attributes including (age, smoking, corpulence, dyslipidemia, family ancestry of CAD, launch division). This came in concurrence with Mohammed et al. [11] who found similar outcomes.

In an investigation done by Puymirat et al. [12], they found that Patients remembered for the DES bunch were more youthful $(81 \pm 4$ versus $82 \pm 4$; $\mathrm{P}=$ $0.007)$ and had a higher weight file $(27 \pm 4$ versus $26 \pm$ $4 ; \mathrm{P}=0.02$ ) than those in the BMS gathering. Likewise, they found that there was no huge distinction in regards to smoking, hyperlipidemia, family ancestry of CAD and discharge part.

In our examination hypertension was more typical in DES bunch than BMS however didn't arrive at measurably noteworthy distinction. In bunch DES and BMS, hypertension was available in $46 \%$ and $40 \%$ separately.

This came in conflict with Mohammed et al. [11] who found that there was a factually huge contrast among the two gatherings with respect to hypertension which was progressively normal in DES gathering. In bunch DES and BMS, hypertension was available in $86 \%$ and $54 \%$ separately.

Ortolani et al. [13] found that there was no factually critical contrast among the two gatherings with respect to hypertension, hypercholesterolemia and smoking.

In the current examination, there was no measurably distinction between the two gatherings concerning gauge angiographic and procedural information including (guilty party vessel, site of injury, sort of sore, reference measurement, stent breadth and stent length). This came in concurrence with Mohammed et al. [11] who found similar outcomes.

Puymirat et al. [12] found that there was no measurably distinction between the two gatherings concerning offender vessel, stenosis seriousness, stent width and reference vessel breadth while there was factually critical contrast with respect to sore and stent length.

In conflict with our investigation, Ortolani et al. [13] found that there was a measurably huge contrast among the two gatherings with respect to offender vessel, reference distance across, stent measurement and stent length. This distinction might be because of their investigation was on diabetic patients.

In the present examination, as in regards to injury seriousness there was no noteworthy distinction between the two gatherings. In DES bunch the sore seriousness went from 80 to $95 \%$ with a mean $90 \%$, while in BMS bunch the injury seriousness extended from 80 to $96.25 \%$ with a mean $90 \%$.

In conflict with our investigation, Mohammed et al. [11] found that as in regards to the pattern angiographic and procedural information there was critical distinction between the two gatherings as per sore seriousness. In DES bunch the sore seriousness ran from 82.67 to $86.32 \%$ with a mean $84.5 \pm 6.4$, while in BMS bunch the injury seriousness ran from 79.13 to $82.86 \%$ with a mean $81 \pm 6.54$. 
In the current examination, there was no huge contrast among DES and BMS bunch with respect to clinical results during development. This came in concurrence with Mohammed et al. [11] who found that the utilization of medication eluting stent versus cobalt chromium stent was related no distinction in death, nonfatal myocardial localized necrosis and coronary supply route sidestep unite during development.

In the present examination as with respect to our Primary End Point which was the rate of MACE (Death, MI, CABG, ISR and TVR) for a 6-month development, major unfavorable heart occasions happened in DES bunch in two patients (4\%) and was lower than BMS gathering. As in BMS gathering, three patients $(6 \%)$ with no factual noteworthiness. This came in concurrence with Mohammed et al. [11] who found that major unfavorable heart occasions happened in DES bunch in three patients (6\%). As in BMS gathering, four patients $(8 \%)$ with no measurable noteworthiness.

Additionally, in concurrence with our investigation, Ortolani et al. [13] found that correlations between the DES and BMS bunches demonstrated that patients rewarded with DES had a non-noteworthy lower danger of MACE and a lower danger of TVR.

Additionally, Puymirat et al. [12] found that the paces of TVR and MACE were lower in the DES bunch than BMS gathering.

In the current investigation, no patient kicked the bucket during follow up period (during GABG) in DES gathering while one patient in BMS bunch passed on because of obscure reason with no huge distinction. This came in concurrence with Mohammed et al. [11] who found that one patient kicked the bucket during follow up period (during GABG) in DES gathering and one patient in BMS bunch with no critical distinction.

In the present examination, two patients created MI in DES gathering and 3 patients in BMS bunch which is considered not huge. TVR happened in DES bunch in one patient $(2 \%)$ and in three patients $(6 \%)$ in BMS bunch with no measurable importance. CABG happened in one patient (2\%) in BMS gathering, while it didn't happen in DES bunch with no measurable hugeness. Instent restenosis happened in DES bunch in two patients $(4 \%)$, while in BMS bunch three patients $(6 \%)$ with no measurable noteworthiness.

This came in concurrence with Mohammed et al. [11] who found that two patients created MI in DES gathering however MI didn't happen in BMS bunch which is considered not critical. TVR happened in DES bunch in three patients $(6 \%)$ and in a similar number of patients in BMS bunch with no factual importance. CABG happened in two patients $(4 \%)$ in DES gathering, while it didn't happen in BMS bunch with no measurable essentialness. Instent restenosis happened in DES bunch in three patients $(6 \%)$, while in BMS bunch four patients $(8 \%)$ with no factual centrality.
Our outcomes came in concurrence with the ENDEAVOR II randomized controlled preliminary to assess the drawn out clinical and financial results for subjects accepting Endeavor sedate eluting versus Driver uncovered metal stents (both Medtronic Cardio Vascular, Santa Rosa, California). From 1,197 subjects randomized to get Endeavor $(\mathrm{n}=598)$ versus Driver ( $\mathrm{n}$ = 599) stents, the utilization of Endeavor versus Driver decreased a 4-year target vessel revascularization rates per 100 subjects (10.4 versus 21.5; contrast:- 11.1; $95 \%$ certainty span $[\mathrm{CI}]$ : -16.0 to $-6.1 ; \mathrm{p}<0.001)$, with no distinction in the rates per 100 subjects of death $(5.0$ versus 5.2 ; distinction: -0.2 ; $95 \% \mathrm{CI}$ : -2.7 to $2.4 ; \mathrm{p}=$ $0.90)$ or nonfatal myocardial localized necrosis $(3.2$ versus 4.4 ; distinction: -1.2 ; $95 \% \mathrm{CI}$ : -3.4 to $1.0 ; \mathrm{p}=$ $0.29)$ [14].

In conflict with our investigation, the ENDEAVOR II preliminary found a higher occurrence of TVR in the cobalt chromium stents bunch with factually critical contrast between the two gatherings, because of numerous elements including that about $33 \%$ of patients had multivessel CAD and type C sores. Likewise $22.2 \%$ of patients were diabetic. At last, most subjects got pre-treatment with expand angioplasty and expanded term of follow-up period. While in our examination there was low frequency of TVR with no measurably noteworthiness distinction in the two gatherings because of modest number of patients included. All patients were non diabetic and the greater part of them with type (A,B) injuries [14].

BASKE Ttrial (BAsel Stent Cost Effectiveness preliminary) revealed the way that it is obscure which patients advantage most from medicate eluting stents (DES) against exposed metal stents (BMS) in a drawn out clinical result. Information from 826 back to back patients with angioplasty, randomized 2:1 to DES versus BMS, with a 18-month follow-up for cardiovascular passing/myocardial localized necrosis (MI) and non-MI-related objective vessel revascularization (TVR) were examined for associations between stent type and patient/vessel attributes foreseeing occasions. Paces of 18-month TVRs were lower with DES versus BMS use (7.5 versus $11.6 \%, \mathrm{P}=0.05$ ), yet comparative for the two stents with respect to heart passing/MI (DES, 8.4\%; BMS, 7.5\%; P =0.70) [15].

Besides, our outcomes in BMS bunch were additionally in concurrence with the clinical and angiographic examination in Class Study which was an imminent, nonrandomized, multicenter study intended to evaluate the security and viability of a cobaltchromium amalgam based stent (Driver) in patients with steady or temperamental angina pectoris. A sum of 203 sores were treated in 202 selected patients. The event of MACE was $4.0 \%$, with TLR representing $1.0 \%$, Q wave MI for $0 \%$, non-Q wave MI for $2.5 \%$ and passings representing $1.5 \%$. This investigation exhibited that the Driver cobalt-chromium compound stent can be utilized with a low half year occurrence of major unfriendly heart occasions, a low half year 
parallel restenosis rate, and a high angiographic and procedural achievement [16].

Our outcomes are likewise in concurrence with the Vision library, in which MACE was $6.2 \%$, with TLR representing $4.3 \%$, Q wave MI for $0.4 \%$, non-Q wave MI for $0.45 \%$ and passings representing $1.2 \%$. Concerning the Driver library, the MACE was $4 \%$ with $3.4 \%$ TLR, no different entanglements were found [17].

While Shishehbor et al., found that 832 passings happened over a 4.5-year stretch among 8,032 patients. Of these, 6,053 got a DES and 1,983 patients had a BMS. All-cause mortality was fundamentally lower in unadjusted and balanced Cox corresponding models with DES (peril proportion: $0.62,95 \%$ certainty stretch: 0.53 to $0.73 ; \mathrm{p}<0.001)$. This investigation uncovered that DES was related with lower mortality in this "genuine world" setting [18].

\section{Conclusion}

The use of drug eluting stent versus cobalt chromium stent was associated with a reduction in target vessel revascularization in small artery stenosis through 6-month follow-up with no difference in death and nonfatal myocardial infarction.

\section{References}

[1] L. Pendyala,"Drug-eluting stents: present and future," Cardiovasc. Hematol. Agents Med. Chem. (Formerly Curr. Med. Chem. Hematol. Agents); Vol. 6(2), PP.105-115, 2008.

[2] A. R. Gruentzig, "Transluminal dilatation of coronary artery stenosis," Lancet.; Vol. 1(3), p. 263, 1978.

[3] P. W. Serruys , "A comparison of balloonexpandable-stent implantation with balloon angioplasty in patients with coronary artery disease," N. Engl. J. Med.; Vol. 331(8), PP.489495, 1994.

[4] J. E. Sousa ,"Lack of neointimal proliferation after implantation of sirolimus-coated stents in human coronary arteries: a quantitative coronary angiography and three-dimensional intravascular ultrasound study," Circulation.; Vol. 103(2), PP.192-195, 2001.

[5] J. Pache, "Kastrati A, Mehilli J, Schuhlen H, Dotzer F, Hausleiter J, Fleckenstein M, Neumann FJ, Sattelberger U, Schmitt C, Muller M, Dirschinger J, and Schomig A," Intracoronary stenting Angiogr. results strut Thick. Eff. restenosis outcome trial. J Am Coll Cardiol.; Vol. 41, PP.1283-1288, 2003.

[6] S. Aziz, J. L. Morris, R. A. Perry, "Late stent thrombosis associated with coronary aneurysm formation after sirolimus-eluting stent implantation," J Invasive Cardiol.; Vol. 19(4), PP.E96-8, 2007.

[7] D. H. Steinberg ,R. Waksman, "Drug- Eluting Stent Thrombosis vs Bare Metal Stent Restenosis: Finding the Lesser of Two Evils," Am. Heart Hosp. J.;Vol. 5(3), PP.151-154, 2007.

[8] M. Joner ,"Endothelial cell recovery between comparator polymer-based drug-eluting stents," J. Am. Coll. Cardiol.; Vol. 52(5), PP.333-342, 2008.

[9] C. Briguori , "In-stent restenosis in small coronary arteries: impact of strut thickness," J. Am. Coll. Cardiol.; Vol. 40(3), PP.403-409, 2002.

[10]L. T. Burgers ,"Treatment variation in stent choice in patients with stable or unstable coronary artery disease," Netherlands Hear. J.; Vol. 24(2), PP.110 $119,2016$.

[11] Y. E. Mohammed, A. Roza, S. Elzogby, A. Aly, and M. Mokarab, "Efficacy Of Drug Eluting Stents Versus Cobalat Chomium Stents In Small Coronary Artery Stenosis In Non Diabetic Patients," J. Am. Sci.; Vol. 11(1), 2015.

[12]E. Puymirat ,"Safety and effectiveness of drugeluting stents versus bare-metal stents in elderly patients with small coronary vessel disease," Arch. Cardiovasc. Dis.; Vol. 106(11), PP.554-561, 2013.

[13]P. Ortolani ,"CLINICAL PERSPECTIVE ," Circulation.; Vol. 117(7), PP.923-930, 2008.

[14]E. L. Eisenstein ,PCV59 ECONOMIC ANALYSIS OF THE ENDEAVOR DRUGELUTING STENT VS. THE DRIVER BARE METAL STENT: RESULTS FROM THE ENDEAVOR II TRIAL," Value Heal.; Vol. 12(3), PP.A152, 2009.

[15]H.-P. B.-L. Rocca, C. Kaiser, M. Pfisterer, "Targeted stent use in clinical practice based on evidence from the Basel Stent Cost Effectiveness Trial (BASKET)," Eur. Heart J.; Vol. 28(6), PP.719-725, 2007.

[16] V. Legrand,"Clinical and angiographic analysis with a cobalt alloy coronary stent (driver) in stable and unstable angina pectoris," Am. J. Cardiol.; Vol. 97(3), PP.349-352, 2006.

[17]D. J. Kereiakes ,"Usefulness of a cobalt chromium coronary stent alloy,” Am. J. Cardiol.; Vol. 92(4), PP.463-466, 2003.

[18] M. H. Shishehbor , "Long-term impact of drugeluting stents versus bare-metal stents on all-cause mortality," J. Am. Coll. Cardiol., Vol. 52(13), PP.1041-1048, 2008. 